\title{
A la recherche de la fonction de l'homologue mammifère du gène de drosophile Suppressor of Hairless
}

Le gène de drosophile Suppressor of Hairless $[\mathrm{Su}(H)]$ a été identifié à partir de son interaction avec le gène Hairless $(H)[1]$. Ce dernier gène doit son nom à l'un de ses phénotypes associés, la perte des soies, ou microchaetes, organes sensoriels de la drosophile adulte. Ce phénotype apparaît comme l'opposé de celui des gènes neurogéniques, tels que $\operatorname{Notch}(N)$ [2-6]. L'analyse moléculaire de Hairless ne donne que peu d'indications sur sa fonction: son produit est une protéine basique, riche en sérine, sans aucune parenté avec une quelconque protéine connue $[3,4]$. Le gène $[S u(H)]$ a été cloné récemment, d'une part, sur la base de ses propriétés génétiques chez la drosophile par F. Schweisguth et J. Posakony, à San Diego (CA, USA) [7] et, d'autre part, comme homologue du gène de souris $J \kappa$-recombination signal binding protein $(R B P-J \kappa)$ par l'équipe japonaise de T. Honjo (Kyoto, Japon) $[8,9]$. Un gène homologue a été trouvé dans l'espèce humaine. Comme son nom l'indique, on pensait que la protéine RBP-Jк jouait un rôle dans la recombinaison des gènes d'immunoglobulines. Cette idée était fondée sur deux données : la protéine RBP-Jк avait été isolée à l'origine grâce à sa liaison à une séquence signal de recombinaison $\mathrm{V}(\mathrm{D}) \mathrm{J}$ de type JK [10] et comportait, en outre, un domaine présentant une similitude de séquence avec la famille des intégrases [11]. Ce domaine semblait conservé dans la protéine de drosophile.

La drosophile est un animal plus maniable que la souris pour les études de génétique moléculaire. On a effectué une mutagenèse in vitro du gène de drosophile, au niveau des sites présumés importants pour la fonction recombinase de la protéine. Ces gènes mutés ont été injectés aux embryons, et les mouches transgéniques obtenues ont permis de montrer que le domaine "intégrase" n'a aucune signification fonctionnelle chez la drosophile [12]. Dans le même temps, on montrait que la liaison à la séquence signal de recombinaison était un artefact [13]. Il n'en restait pas moins que la protéine RBP-JK est nucléaire et se lie à l'ADN au niveau d'une séquence spécifique, différente des fameux heptamère et nonamère caractéristiques des séquences de recombinaison des immunoglobulines. Quelle est alors la fonction de la protéine $\mathrm{Su}(\mathrm{H}) /$ RBP-JK ?

Des études récentes chez les mammifères apportent un nouvel éclairage sur la protéine RBP-Jк. Le produit du gène $E B N A 2$ du virus Epstein-Barr est un puissant activateur de transcription. Cependant, il est incapable de se lier par lui-même à l'ADN. Il interagit avec une protéine, nommée $C$ promoter binding factor (CBF-1), qui lui fournit un domaine de liaison spécifique à l'ADN. CBF-1 est identique à RBP-Jא [13-15]. Une fonction de répresseur de transcription a été aussi mise en évidence pour RBP-Jא [16]. Enfin, RBP-JK est identique au facteur humain KBF2, une protéine nucléaire qui se lie spécifiquement aux sites $\mathrm{kB}$, cibles du facteur de transcription NFKB [17].

Des travaux récents sur la drosophile éclairent le rôle de la protéine $\mathrm{Su}(\mathrm{H})$ et la placent au cœur du dispositif de la neurogenèse. $\mathrm{Su}(\mathrm{H})$ est une protéine qui se lie à l'ADN, et son domaine de liaison a été précisé. Il ne ressemble à rien de connu parmi les facteurs de transcription [17]. Cependant, on a montré que la protéine $\mathrm{Su}(\mathrm{H})$ est non pas nucléaire, mais cytoplasmique, lorsqu'elle est exprimée en même temps que le récepteur transmembranaire Notch dans des cellules en culture [18]. On sait le rôle clé de Notch dans la décision que prend une cellule du neurectoderme de s'engager ou non dans la voie neurale [6]. Il est probable que la protéine Notch joue un grand rôle dans d'autres décisions binaires de différenciation chez la drosophile et chez d'autres organismes, du nématode aux vertébrés $[19,20]$. Notch est un récepteur membranaire, qui présente des domaines de structure semblable au récepteur EGF des vertébrés. Une autre molécule membranaire, la protéine Delta, agit comme signal pour la protéine Notch, enclenchant le programme de différenciation. Jusqu'à présent, la façon dont ce signal était transmis au noyau restait mystérieuse. Lorsque Delta se lie à Notch, la protéine $\mathrm{Su}(\mathrm{H})$ se déplace du cytoplasme vers le noyau [18]. De plus, la rétention de $\mathrm{Su}(\mathrm{H})$ dans le cytoplasme est due à une interaction directe avec la protéine Notch, au niveau de motifs ankyrine de cette protéine [18].

L'interaction de l'équipe de Biologie moléculaire de l'Expression génique humaine d'A. Israël à l'Institut Pasteur et celle de F. Schweisguth, au laboratoire de Biologie Moléculaire du Développement de l'Institut JacquesMonod, a permis de pousser plus loin la comparaison entre les protéines humaine et de drosophile [17]. Une autre question a été posée : puisque le gène $S u(H)$ est connu pour son interaction génétique avec Hairless, quel est le mécanisme de cette interaction? Ces deux équipes ont montré que la protéine $\mathrm{Su}(\mathrm{H})$ interagit directement avec la protéine Hairless, in vitro. Cela est vrai aussi de la protéine RBP-Jк. Dans les deux cas, l'interaction avec la protéine Hairless inhibe l'activité transcriptionnelle de $\mathrm{Su}(\mathrm{H}) / \mathrm{RBP}-J \kappa$. Ces nouveaux résultats laissent penser qu'un 
même mécanisme d'inhibition par interaction protéine-protéine est à l'œuvre aussi bien pour régler l'activité de la protéine de drosophile $\mathrm{Su}(\mathrm{H})$ que celle de la protéine humaine RBP-Jк. Dans ce cas, y a-t-il un homologue humain du gène Hairless? De nouvelles recherches en perspective, pour ceux qui s'intéressent aux mécanismes de la détermination cellulaire, chez l'homme... et chez la drosophile

\section{RÉFÉRENCES}

1. Ashburner M. The genetics of a small autosomal region of Drosophila melanogaster containing the structural gene for alcohol dehydrogenase. III. Hypomorphic mutations affecting the expression of Hairless. Ge netics $1982 ; 101$ : 447-59.

2. Bang AG, Hartenstein V, Posakony JW. Hairless is required for the development of adult sensory organ precursor cells in Drosophila. Development 1991; 111 : 89-104

3. Bang AG, Posakony JW. The Drosophila gene Hairless encodes a novel basic protein that controls alternative cell fates in adult sensory organ development [published erratum appears in Genes Dev 1992 6(11) : 2233]. Genes Dev $1992 ; 6$ : 1752-69.

4. Maier D, Stumm G, Kuhn K, Preiss A Hairless, a Drosophila gene involved in neural development, encodes a novel, serine rich protein. Mech Dev $1992 ; 38$ : 143-56.

5. Schweisguth F, Posakony JW. Antagonistic activities of Suppressor of Hairless and Hairless control alternative cell fates in the Drosophila adult epidermis. Development 1994; $120: 1433-41$

6. Ghysen A, Dambly-Chaudière C. Le développement des organes sensoriels chez la drosophile. médecine/science $1995 ; 11: 178$ 88.

7. Schweisguth F, Posakony JW. Suppressor of Hairless, the Drosophila homolog of the mouse recombination signal-binding protein gene, controls sensory organ cell fates. Cell $1992 ; 69$ : 1199-212.

8. Furukawa T, Kawaichi M, Matsunami N, Ryo H, Nishida Y, Honjo T. The Drosophila RBP-J kappa gene encodes the binding protein for the immunoglobulin J kappa recombination signal sequence. J Biol Chem $1991 ; 266$ : 23334-40.

9. Furukawa T, Maruyama S, Kawaichi $M$, Honjo T. The Drosophila homolog of the immunoglobulin recombination signal-binding protein regulates peripheral nervous system development. Cell $1992 ; 69: 1191-7$. 10. Hamaguchi Y, Matsunami N, Yamamoto $Y$, Honjo T. Purification and characterization of a protein that binds to the recombination signal sequence of the immunoglobulin JK segment. Nucleic Acids Res 1989 ; $17: 9015-26$.

11. Matsunami N, Hamaguchi $Y$, Yamamoto $Y$, Kuze K, Kangawa $K$, Matsuo $H$, Kawaichi $\mathrm{M}$, Honjo T. A protein binding to the JK recombination sequence of immunoglobulin genes contains a sequence related to the integrase motif. Nature $1989 ; 342: 934-7$.

12. Schweisguth F, Nero P, Posakony JW. The sequence alignement of the Drosophila Suppressor of Hairless protein to the integrase domain has no functional significance in vivo. Dev Biol $1994 ; 166: 812-4$.

13. Grossman SR, Johannsen E, Tong X, Yalamanchili R, Kieff E. The Epstein-Barr virus nuclear antigen 2 transactivator is directed to response elements by the Jk recombination signal binding protein. Proc Natl Acad Si USA 1994 ; 91 : 7568-72.

14. Henkel T, Ling PD, Hayward SD, Peterson MG. Mediation of Epstein-Barr virus EBNA2 transactivation by recombination signal-binding protein JK. Science $1994 ; 265$ : 92-5.

15. Zimber-Strobl U, Strobl LJ, Meitinger C, Hinrichs R, Sakai T, Furukawa T, Honjo T,
Bornkamm GW. Epstein-Barr virus nuclear antigen 2 exerts its transactivation function through interaction with recombination signal binding protein RBP-JK, the homologue of Drosophila Suppressor of Hairless. EMBO J 1994 ; 13 : 4973-82.

16. Dou S, Zeng X, Cortes P, ErdjumentBromage $\mathrm{H}$, Tempst P, Honjo T, Vales LD. The recombination signal sequence-binding protein RBP-2N functions as a transcriptional repressor. Mol Cell Biol 1994; 14 : 33109.

17. Brou C, Logeat F, Lecourtois M, Vandekerckhove J, Kourilsky P, Schweisguth F, Israël A. Inhibition of the DNA-binding activity of Drosophila Suppressor of Hairless and of its human homolog, KBF2/RBP-Jא, by direct protein-protein interaction with Drosophila Hairless. Genes Dev 1994 : $8:$ : 2491-503. 18. Fortini ME, Artavanis-Tsakonas S. The Suppressor of Hairless protein participates in Notch receptor signaling. Cell $1994 ; 79$ : 273-82.

19. Weinmaster G, Roberts VJ, Lemke G. A homolog of Drosophila Notch expressed during mammalian development. Development 1991 ; 113 : 199-205.

20. Kopan R, Weintraub H. Mouse notch: expression in hair follicles correlates with cell fate determination. J Cell Biol 1993 ; $121: 631-41$.

\section{Jean Deutsch}

Laboratoire d'évolution moléculaire, université Pierre-et-Marie-Curie, 9, quai Saint-Bernard, 75252 Paris Cedex 05, France.

\section{TIRÉS À PART}

J. Deutsch. 